\title{
The influence of city reputation on T-KIBS concentration
}

\section{Pedro Torres}

CeBER and Faculty of Economics, University of Coimbra

Av. Dias da Silva, 165

3004-512 Coimbra - Portugal

Phone: +351 239 790584, Fax: +351 239790514

E-mail: pedro.torres@uc.pt

\section{Pedro Godinho}

CeBER and Faculty of Economics, University of Coimbra

Av. Dias da Silva, 165

3004-512 Coimbra - Portugal

Phone: +351 239 790571, Fax: +351 239790514

E-mail: pgodinho@fe.uc.pt

Corresponding author: Pedro Torres

Word count: 8675 


\title{
The influence of city reputation on T-KIBS concentration
}

\begin{abstract}
In a context of increasing intercity competition, one of the major goals of the cities is to attract business services, in particular knowledge intensive business services (KIBS). In spite of the recognized importance of some location determinants, already identified in the literature, not all of the determinants of KIBS location choices are known. Studies that considered city reputation as a possible antecedent of KIBS location are scarce. This study aims to examine the influence of city reputation on technology-KIBS urban concentration. Building on the theoretical arguments that support the geographic centrality of high-order services, the study shows that different combinations of antecedent conditions can justify a high concentration of technology-KIBS (T-KIBS) in urban areas, including the combination of city reputation with access to clients. The results support the idea that geographical proximity to clients is also important in technology-related industries, in particular the ones that are knowledge intensive. The findings suggest that tourism policies that enhance the city reputation can be included in cities' strategies designed to attract business services. Furthermore, it is highlighted that policymakers do not need to improve all conditions to improve the city competitiveness and they can use different combinations of factors to attract T-KIBS.
\end{abstract}

Keywords: KIBS, business services, location choices, city reputation, tourism.

This is an Accepted Manuscript of an article published by Taylor \& Francis in [European Planning Studies] on [2019], available online: http://www.tandfonline.com/ 10.1080/09654313.2019.1700484. 


\section{Introduction}

Cities and regions recently emerged as key organizing units for innovation, creativity and entrepreneurship through knowledge-based capitalism (Florida, Adler, \& Mellander, 2017). There is a structural change from manufacturing to service-based economies, and business services are growing much faster in metropolitan regions (Henning, 2019). In this context, knowledge-intensive business services (KIBS) are a constitutive element of innovation systems (Corrocher \& Cusmano, 2014). KIBS play a critical role as co-creators, carriers and diffusers of knowledge (Jacobs, van Rietbergen, Atzema, van Grunsven, \& van Dongen, 2016).

By definition, KIBS correspond to services that involve economic activities intended to result in the creation, accumulation, and dissemination of knowledge (Miles et al., 1995). The KIBS category includes non-material firms that provide intangible and highly personalized services that act as external sources of knowledge to their clients (Czarnitzki \& Spielkamp, 2003). The literature distinguishes two kind of KIBS: advisory services, usually termed professional KIBS (P-KIBS), often seen as intensive users of technology; and technical services, also named technology-KIBS (T-KIBS), which use, develop, and carry technology. The presence of KIBS in urban areas has been considered critical (see, e.g., Muller and Zenker, 2001, Czarnitzki \& Spielkamp, 2003). It is often assumed that future urban employment will increasingly depend on it (e.g., Wood, 2006). Thus, understanding the conditions that influence the location of KIBS has been considered an important research topic (e.g., Wood, 2002, 2009).

The study of the determinants of firms' location has been a major question for researchers (e.g., Kahn \& Henderson, 1992; Autant-Bernard, Mangematin, \& Massard, 2006) and past studies have focused on the factors that influence the location of specific types of firms in urban areas (e.g., Frenkel, 2001). Regarding business services, recent literature has attempt to identify the conditions that influence location choices (e.g., Rubalcaba, Gallego, Gallo, \& Garrido, 2013; Camacho-Ballesta, Melikhova, \& Hernández-Peinado, 2014). 
Nevertheless, the dynamics of business services are "complex, contradictory and themselves evolving" (Martinelli, 1991, p. 79). More recently, a "conjunctural” approach to urban analysis has been advocated, which requires the recognition of contextual complexity (e.g., Peck, 2017). Furthermore, the knowledge industry has unique characteristics in terms of its location (e.g., it usually requires face-to-face communications) and not all of the determinants of KIBS location choices are known (Yamamura \& Goto, 2018).

In a context of global intercity competition, cities are looking forward to increase their competitiveness, in which the cities' positioning and attractiveness plays an important role (Anttiroiko, 2014). Among the possible strategies for increasing urban attractiveness, cities can provide premises for international agencies, host major international events or promote tourism (Kresl \& Fry, 2005). Marketing-based approaches are gaining traction because other strategies, such as the investment in the provision of urban facilities is increasingly seen has insufficient by policy-makers (Anttiroiko, 2014). The city image reflects the influence of a city reputation. City reputation can by defined as "the aggregation of a single stakeholder's perceptions of the capacity of the city to meet demands and expectations of many city stakeholders" (DelgadoGarcia, de Quevedo-Puente, \& Blanco-Mazagatos, 2018, p.2). City reputation is an intangible asset (e.g., Roberts \& Dowling, 2002) and can be a source of competitive advantage (e.g., Aula \& Harmaakorpi, 2008; Wæraas, 2015). It has been suggested that city reputation can influence city performance, in particular on the creation and development of new firms (Delgado-Gacia et al., 2018). However, there is a scarcity of empirical research on the outcomes of city reputation; furthermore, few studies have considered city reputation as an antecedent of KIBS location.

This study aims to contribute to KIBS literature by examining the influence of city reputation on T-KIBS location. By taking a configurational approach it is acknowledged that different combinations of conditions may lead to the same outcome, i.e. high concentration of 
T-KIBS in urban areas. This approach assumes that specific conditions are not necessary nor sufficient to obtain the outcome of interest, but in combination with other conditions that can lead to a certain outcome. Therefore, the study aims to identify the combination of factors that justify the high concentration of T-KIBS in some cities, including city reputation (which is reflected by tourism) as a potential antecedent. Thus, besides the use of principal components analysis (PCA) to identify the factors, and the use of multiple regression analysis (MRA) to determine its impact, qualitative comparative analysis (QCA) is employed to uncover the combinations of conditions that lead to higher concentration of T-KIBS in certain cities. QCA adds two notable dimensions to the analysis. First, the ability to unravel causally complex structures, such as equifinality (Fiss, 2011), meaning that different combinations of antecedent conditions can lead to the same outcome. Second, the ability to identify combinations of conditions (Ragin, 2008).

Using public data from Eurostat regarding Germany's major cities, the study identifies four factors that influence T-KIBS location: i) access to clients, ii) land use intensity, iii) city reputation, and $i v$ ) household income. Considering these factors, the findings provide two main contributions to the literature. First, the results show that no condition alone is either necessary or sufficient to account for T-KIBS location; two alternative configurations that explain high T-KIBS concentration were identified. Access to clients is present in the two configurations, suggesting that geographical proximity to clients is one of the most important factors for location choices. This finding supports the idea that face-to-face interactions are also important in the ICT industry (which is not consensual in the literature), suggesting the geographical proximity with clients contributes to the production of knowledge, which often involves tacit knowledge that is only conveyed through direct exchanges. Second, the study shows that city reputation can be an important antecedent of T-KIBS location, when combined with access to clients. City reputation relates to culture and entertainment, which will attract tourists. Thus, it 
is suggested that tourism policies can be included in cities' strategies that aim to attract business services, in particular the creation and development of T-KIBS. Furthermore, it is emphasized that policy-makers can use different combinations of factors to improve their competitiveness.

The remainder of this article is structured as follows. The next section provides the theoretical background. Section 3 describes the data and the methodology. In Section 4, the results are reported. Finally, in Section 5, the results are discussed and the main conclusions, implications, and limitations are presented.

\section{Theoretical background}

\subsection{The importance of T-KIBS for cities' competitiveness}

One of the most important characteristics of post-industrial cities is that its employment is based on advanced, knowledge-intensive, high value adding and IT-enabled services (Anttiroiko, 2018). The KIBS main goal is to provide services to other business organizations and its main function is to produce and introduce knowledge (Miles, 2005). The business services sector is closely linked to investment, innovation, and technological change (Coffey, 1996). The literature suggests that the presence of KIBS contributes to regions competitiveness and is an impetus for innovation and growth (see, e.g., Miles et al., 1995; Muller \& Zenker, 2001, Czarnitzki \& Spielkamp, 2003). Recently, it has been recognized that cities and regions are key organizing units for innovation through knowledge-based capitalism (Florida et al., 2017). KIBS are a constitutive element of innovation systems (Corrocher \& Cusmano, 2014). Indeed, the literature has widely acknowledged that KIBS play a critical role as co-creators, carriers and diffusers of knowledge (Slimmie \& Strambach, 2006; Strambach, 2008; Jacobs et al., 2016). A comparison of the cities with higher T-KIBS scores with the innovation index 
(provided by the Innovation Cities Program ${ }^{1}$ ) provides some evidence of a link between TKIBS and innovation. The German cities better placed in this index also have a high percentage of T-KIBS jobs. Thereby, the importance of T-KIBS for city competitiveness seems to be corroborated. Thus, the ability to attract KIBS can play an important role for city prospects.

Cities have long been seen as a source of knowledge diversity and key to innovation activities (Jacobs, 1969). The idea that the city can be an epicenter of innovation is linked to agglomeration of activities and to the potential to lower costs of transferring knowledge and people between city actors (Aslesen \& Jakobsen, 2007). Development of knowledge hubs has become a target for policy-makers, reflecting the tension between global and local in the knowledge-based economy (Corrocher \& Cusmano, 2014). The increasing demand for services justifies in great extent the growing importance of cities (Sassen, 2000). Moreover, KIBS play an important role since these category of business services generates, converts and/or diffuses knowledge through the system. T-KIBS assume a particular importance among KIBS. KIBS activities involve the creation, validation, and application of specialized knowledge that aim to solve clients' challenges (Herstad \& Ebersberger, 2015). This implies the development of a high degree of knowledge and innovation (Yang \& Yan, 2010; Camacho-Ballesta et al., 2014), which can foster the competitive base of cities. There is evidence that KIBS start-ups tend to be more frequently located where the KIBS sector is already large (Anderson \& Hellerstedt, 2009; Jacobs et al., 2016). This phenomenon creates a dynamic that benefits mostly central metropolitan areas (Camacho-Ballesta et al., 2014). The agglomeration advantages that result from urbanization economies can foster innovation (Florida et al., 2017).

\footnotetext{
${ }^{1}$ http://www.innovation-cities.com/innovation-cities-index-2015-europe/9617
} 


\subsection{Urban agglomerations, geographical proximity and T-KIBS location}

The existence of large markets provided by high-density urban agglomerations tends to stimulate the creation of KIBS start-ups (Anderson \& Hellerstedt, 2009). It can be argued that there are clusters of KIBS employment, which can be designated as localization effects (Shearmur, 2012). Furthermore, the existence of specialized clusters of business services can enhance profitability (Koster et al., 2014). The link between space and innovation is an important research topic, but the findings are somehow contradictory.

Some authors argued that the proximity between actors promotes interactions that can lead to innovations (e.g., Cooke, Heidenreich, \& Braczyk, 2004; Porter, 2003), but it has also been claimed that innovations dynamics are not necessarily local (e.g., Boschma, 2005; Torre \& Rallet, 2005; Torre, 2008; Shearmur, 2012). Agglomeration economies can be reflected in innovation that results from proximity between actors (Breschi, 2008). While agglomeration economies occur — by definition — in localized clusters (Shearmur, 2012), innovation dynamics may be linked to opportunities for interactive learning that may occur at the national level (Lundvall, 2007). However, it has been suggested that agglomeration economies tend to occur at a city level (Parr, 2002). The literature claims that agglomeration economies results mainly of cost saving mechanisms (e.g., Puga, 2010). Inspired by Shearmur (2012), this study considers the possible existence of two types of agglomeration economies: economies of scale related to cost savings attributable to co-location of similar activities, which can be designated by localization economies; and economies of scope related to cost savings attributable colocation of activity in general, which can be designated by urbanization economies. While localization effects refer to clusters of KIBS employment, urbanization effects refer to cluster of total employment.

When immediate market knowledge is important, there is a need for co-location with clients and competitors (McCann, 2007). Clients have been considered the most important 
source of knowledge (Jacobs et al., 2016). The client interface enables the co-creation of new knowledge (Lambregts, 2008). However, the emergence of information and communication technologies (ICT) facilitates knowledge exchange, and, although the geographical proximity remains essential for knowledge transfer, it has been suggested that this proximity could be temporary (Torre, 2008). Nevertheless, despite the trend of decreasing transportation and communication costs, some authors claim that they are and will not be spatially indifferent (e.g., Hall, 1999).

In a knowledge society, we can find explicit, encoded and tacit knowledge. The latter is only conveyed through direct exchanges (Méndez \& Sánchez Moral, 2010). Furthermore, the process of knowledge creation requires a strong interplay between tacit and explicit forms of knowledge (Bentlage, Lüthi, \& Thierstein, 2013). The spatial proximity and face-to-face contacts tend to be critical to knowledge creation and application (Storper \& Venables, 2004). It has long been argued that the need for face-to-face justifies the concentration of KIBS (e.g., Martinelli, 1991). In the same vein, recent research suggests that the proximity to clients is key to KIBS, irrespective of their size, location or category (Jacobs et al., 2016). T-KIBS are highorder services that produce and sell knowledge to their customer. This involves a complex interaction with customers and entails an interactive learning process (Hertog, 2000). For example, a study focused on the clustering of software companies in Oslo stresses that its activity is project-based, which requires a close interaction among companies, decisionmakers, IT personnel of important customers, and software consulting companies themselves (Isaksen, 2004). Thus, although some authors contend that there is a paradigm shift in urban systems, suggesting that central places are being displaced by networks, the concentration of high-order services still has theoretical and empirical support (further discussion on this topic can be seen on Shearmur \& Doloreux, 2015). 


\subsection{City reputation and other determinants of T-KIBS location choice}

Past research has identified several factors that explain business services location (e.g., Rubalcaba et al., 2013; Rubalcaba \& Gago, 2003). These factors can be divided into demandoriented factors and supply factors (Rubalcaba et al., 2013). The demand-oriented dimension includes three main factors: access to clients, degree of economic development, and market dynamism. The supply dimension comprises factors related to the abundance of productive factors, the existence of satisfactory infrastructure and territorial accessibility, and the presence of both a pro-innovation atmosphere and a socially open and culturally diverse environment. The importance of each factor tends to vary at the space level (nations, regions, cities) and depends on the specific nature of the business service (Rubalcaba \& Gago, 2003). As cities are the scope of our analysis, we chose to investigate the demand and supply factors that have the highest influence on the urban concentration of business services.

Rubalcaba and Gago (2003, p.83) classified image and prestige, access to clients, and household income as the most important demand factors and infrastructure and innovative environment as the most important supply factors. Furthermore, as T-KIBS are the focus of this paper, we allocate special attention to the conditions that tend to be more determinant for KIBS location, as follows. Services for which the interaction between the buyer and supplier is intense require physical proximity (Rubalcaba \& Gago, 2003); that is the case of T-KIBS. Thus, access to clients should be an important factor (Shearmur \& Doloreux, 2008). Population density reflects better access to clients (Rubalcaba \& Gago, 2003). Moreover, population density can be considered a proxy for agglomeration effects (Buch, Hamann, Niebuhr, \& Rossen, 2014). Nevertheless, some studies suggested that the proximity to the market is relatively unimportant for high-technology firms (e.g., Frenkel, 2001) and some T-KIBS belong to this firm type. Furthermore, the higher the degree of economic development the 
higher tends to be the demand (Rubalcaba et al., 2013). The gross domestic product per inhabitant is often considered a proxy of cities' level of economic development.

Location-specific amenities are expected to gain more importance in location choice decisions, in a context of declining transport cost (Granger \& Blomquist, 1999). More so in industries characterized by labor-intensity because they affect wages and rents. However, the results obtained by Granger and Blomquist (1999) indicate that urban agglomeration and scale economies remain paramount in location decisions. Infrastructure and territorial accessibility justify the option for some locations against other possibilities (Marshal \& Wood, 1995). Land use can provide an indicator of the degree of infrastructure sophistication. Moreover, it could also be an indicator of economic development. Therefore, it is reasonable to expect land use to be an antecedent condition of high T-KIBS concentration in certain cities.

However, more recently, the importance of marketing-based approaches to improve cities' competitiveness has been recognized, such as promoting tourism, since the investment in the provision of urban facilities is increasingly seen has insufficient (Anttiroiko, 2014). The city image reflects the influence of a city reputation, which is an intangible asset (e.g., Roberts \& Dowling, 2002). Research that addresses this important intangible factor has been scarce. An exception is the work of Delgado-Garcia et al. (2018), which suggests that city planners should improve city reputation. If a city reputation is enhanced, the city is likely to garner additional tourists. Tourism facilitates the exchange of cultures and implies a degree of openness to other cultural practices and, according to Florida (2002), innovation is more likely to occur in societies that are open and culturally diverse.

Research on the relation between tourism and KIBS has been scarce. KIBS provide knowledge-intensive inputs to the business processes of other organizations (Miles, 2005). Therefore, KIBS are sources of knowledge that boost innovation outcomes for their customers (D’Antone \& Santos, 2016). Tourism literature shows that tourism actively cooperates with 
firms from other sectors, including KIBS (Novelli, Schmitz, \& Spencer, 2006; Racherla \& Hu, 2010). Thus, it can be hypothesized that the expansion of city tourism can also influence the concentration of KIBS in certain cities, in particular T-KIBS, because tourism increases the demand for business services, such as ICT. Some cities can be profiled as cities of consumption and culture, in which conventional elements such as tourism and entertainment are emphasized; in this profile, we can find tourist cities, such as Düsseldorf (Anttiroiko, 2018). Arts and culture are associated with the concept of creative cities and the pursuit of strategies that leverage these elements is often linked to a wider progressive agenda that combines it with the ideas of smart growth and sustainability (e.g., Scott, 2006). A recent study suggests that the regional image, which relates to the presence of many amenities and urbanization, influences KIBS' location in Tokyo Metropolitan Area (Yamamura \& Goto, 2018). Likewise, city reputation can be an important determinant of T-KIBS location choices. City reputation relates to its image, which is difficult to assess, but the number of tourists and other visitors could be a proxy indicator for this factor. The presence of amenities related to art and culture could be a key element of city reputation, which in turn will attract more tourists. The development of city tourism will increase the demand for business services, such as T-KIBS, and will require innovations that involve different economic agents. Therefore, the city reputation and the development of city tourism can attract T-KIBS.

Despite of the recognised importance of some factors, this study assumes that none of aforementioned location factors by itself is either necessary or sufficient to justify the high concentration of T-KIBS in certain cities. Rather, it is hypothesized that it is the joint combination of different location factors that influence the clustering of T-KIBS in some cities. Furthermore, it is hypothesized that more than one combination leading to this outcome can be possible, taking in account the configurational approach that guides this research. 


\section{Data and methodology}

To develop the study, public data from Eurostat regarding Germany' major cities was used and information and communication technologies (ICT) services was chosen as a proxy of T-KIBS. These options are justified as follows. Regarding the chosen country, Germany has already been considered an interesting case in past research (Buch et al., 2014) because it presents considerable differences across cities. Regarding the choice of ICT several reasons can be outlined. First, there is evidence that this category assumes a particular importance among KIBS. Second, ICT services are one of the most frequently outsourced functions in the tourism industry (Borodako, Berbeka, \& Rudnicki, 2015), which can be related with city reputation. Third, focusing on ICT will enable an additional contribution regarding the role of geographical proximity. Geographical proximity has become less important because ICT facilitates the exchange of knowledge (e.g., Grabher, 2002), but face-to-face interactions have been considered to be important (e.g., Torre, 2008).

As aforementioned, the data used in this research comes from Eurostat ${ }^{2}$. In the case of Germany, Eurostat considers two spatial unit levels: Core City, namely, a local administrative unit where the majority of the population lives in an urban center of at least 50,000 inhabitants, and Functional Urban Area, namely, a city and its commuting zone. Germany was chosen to facilitate comparisons with previous studies (e.g., Buch et al., 2014) and because it presents considerable differences across cities. Following Rubalcaba et al. (2013), we perform the analysis at the level of Core City, because the values of most indicators (e.g., population density, share of land used for different purposes) represent the city conditions better when the Core City is considered. The city area is from the Local Administrative Units ${ }^{3}$ section of the

\footnotetext{
${ }^{2}$ http://ec.europa.eu/eurostat

${ }^{3}$ http://ec.europa.eu/eurostat/web/huts/local-administrative-units
} 
Eurostat site, and the remaining indicators are from the Cities (Urban Audit) Database ${ }^{4}$. From the available indicators, we defined a set of relevant variables, based on the literature and our objectives. These variables are presented in the leftmost column of Table 1 . The prevalence of T-KIBS in a city is measured by the ratio between the employment in ICT services and the total employment in that city. This ratio will be hereafter referred to as the percentage, or level, of T-KIBS jobs.

Although the Cities (Urban Audit) Database contains data from 2007 to 2016, in many cases, data are unavailable for some indicators and some cities. The data are very often unavailable for the two most recent years, in this case, 2015 and 2016, leading us eliminate these years. Ideally, a single year would be chosen, and data from that year would be used in the analysis. However, data is often missing for some indicators and cities in particular years. Thus, we chose a range of years, namely, 2010 to 2014, and calculated the values of the variables for each city and each year in which data was available. The analysis is based on the average of these values.

Data from 125 German cities are available from the Cities (Urban Audit) Database. For some cities, there were no data concerning some variables for any of the considered years. After eliminating those cities, we had data for 75 cities, including most of the largest German cities. The location of these cities is presented in Figure 1 (cities with a high percentage of TKIBS jobs are indicated by black dots and cities with a low percentage of T-KIBS jobs light grey dots).

(Insert Figure 1 about here)

To explain T-KIBS employment in the German cities, we considered a set of 11 variables. This large number of variables and that some of them are strongly correlated might

\footnotetext{
${ }^{4}$ http://ec.europa.eu/eurostat/web/cities/data/database
} 
cause difficulties in the methods we intended to apply. Therefore, we started by reducing the number of variables by resorting to principal component analysis (PCA). This technique aggregates the original variables in a set of factors that capture most of the variance of the original variables, thus allowing us to reduce the dimensionality of data. With PCA the loss of information is minimized and it is possible to uncover some structure of the relationship between the variables. The factors identified by PCA were then used in a multiple regression analysis (MRA). In this manner, we intended to determine whether a linear relation between the factors would be sufficient for meaningfully explaining the percentage of T-KIBS jobs in different cities. However, the MRA only accounts for linear and symmetric relations between the predictors and the outcome of interest. Hence, complex structures, such as equifinality, would not be identified by the MRA. Therefore, we used an alternative technique that might be able to uncover complex relationships: fsQCA. This technique belongs to a general approach termed QCA (Rihoux, Rezsöhazy, \& Bol, 2011), which has been increasingly applied (see, e.g., Berger, 2016).

QCA techniques examine the relationships between the outcome and all the possible combinations of binary states (i.e., presence or absence) of its predictors, performing a systematic cross-case analysis that allows for the identification of configurations that reflect the conditions for achieving an outcome of interest (Ordanini, Parasuraman, \& Rubera, 2014). FsQCA is based on fuzzy numbers that represent degrees of membership (belonging to the [0, 1] interval) in sets defined by conditions. The method maps the original values of the variables into fuzzy scores based on the specification of three thresholds: a full membership threshold, a non-membership threshold, and a crossover point. The full membership and non-membership thresholds specify the limits beyond which we consider a case to be virtually a full member of the set or virtually outside the set, respectively (Ragin, 2008, p. 88). The crossover point is the value for which there is most ambiguity as to whether a case is more in or more out of the set 
(Ragin, 2008, p. 90). Each of these thresholds translates into a specific fuzzy value — fuzzy values of $0.95,0.05$, and 0.50 are usually used for the full membership and non-membership thresholds and for the crossover point, respectively (see, e.g., Ragin, 2008, chapter 5). Several authors resort to the ninetieth, tenth, and fiftieth percentiles of the values of the original distribution to define these thresholds (e.g., Navarro, Llinares, \& Garzon, 2016; Ryan \& Berbegal-Mirabent, 2016; Torres, Augusto, \& Godinho, 2017, among others). We use this method, with these percentiles, to obtain the membership degrees for the variables.

The analysis of sufficient conditions with fsQCA additionally requires the definition of two thresholds: a frequency threshold and a consistency threshold. The frequency threshold establishes the minimum number of cases that should belong to a given causal combination for it to be included in the causal analysis. When the number of cases is not large (as in this research), a low frequency threshold is often used (e.g., Ragin, 2008, p. 143, recommends a frequency threshold of one or two when the total number of cases is relatively small). Thus, we used a frequency threshold of two, allowing us to use all the available information to obtain results. For the choice of a consistency threshold, several authors recommend avoiding values smaller than 0.75 and preferably using values of 0.80 or higher (e.g., Ragin, 2009, p. 121). To choose a specific value, identifying substantial gaps in the range of the consistency scores for the combinations to be used in the causal analysis is the most recommended procedure (e.g., Ragin, 2009, p. 121). In this study, the only sizeable gap greater than 0.77 occurs for the values between 0.811 and 0.848 . Thus, we defined the consistency threshold inside this gap, choosing a value of 0.82 for this threshold. 


\section{Results}

The PCA confirmed that reducing the original 11 variables to a small number of factors, in this case, four, is possible. These four factors explain almost $88 \%$ of the original variance, showing that replacing the original variables with these factors does not lead to a significant loss of information. The Kaiser-Meyer-Olkin test confirmed the suitability of the data for factor analysis, because the obtained value of 0.721 is clearly larger than the 0.6 or 0.5 thresholds commonly used. For an easier interpretation of the results, a varimax rotation with Kaiser normalization was performed. Table 1 shows the results obtained with PCA. To emphasize the most important variables, only the loadings larger than 0.65 in each factor are shown in the table.

(Insert Table 1 about here)

From Table 1 we observe that the identified factors lend themselves to an agreeable interpretation. The highest explanatory factor explains approximately $34 \%$ of the total variance. The variables with highest loadings in this factor are the economically active population, total employment, and number of companies. This set of variables can be viewed as an indication of the potential clients of T-KIBS in the city; thus, we defined this factor as the "Access to clients." The second most important factor explained approximately $22 \%$ of the total variance, and the variables with highest loadings in this factor were the three variables related to the share of land used for different urban purposes (i.e., industrial, commercial, public, military, and private units; transportation; green urban areas and sports and leisure facilities) and the population density. This set of variables was considered an indication of "Land use intensity." The third factor explained approximately $22 \%$ of the total variance, and the variables with the highest loadings can be a proxy of the city image (i.e., museum visitors, nights spent in tourist accommodation establishments, and number of beds in such establishments). The indicators used in this study to measure city image are in line with past 
studies. For example, Yamamura \& Goto (2018) used food amenities, nightlife amenities, entertainment amenities, sports amenities and public park amenities to measure regional image. In this study, we used the term "city reputation" for this factor instead of city image because it is more closely related to the measures. The fourth factor explained approximately $10 \%$ of the total variance and included only one variable with a loading higher than 0.65 : the average disposable annual household income. This factor was considered to represent the "Household income." The four factors that were extracted are in line in the literature. Rubalcaba and Gago (2003) have suggested that image and prestige (which corresponds to city reputation in this paper), access to clients, and economic income are the most important demand factors. Moreover, these authors claim that infrastructure (which is captured in the land use factor in this paper) is one the most relevant supply factors influencing location choices.

The identified factors were then used in a regression analysis, in which the dependent variable was the percentage of T-KIBS jobs. The main results of this regression are presented in in Table 2. The obtained coefficient of determination $\left(\mathrm{R}^{2}\right)$ is low, 0.27 , but the F-statistic is statistically significant at the $1 \%$ level. This result means that the factors, or at least some of them, are related to the percentage of T-KIBS jobs, but a linear combination of these factors is only able to explain a limited amount of the variance of the dependent variable across the considered cities. Additionally, only two of the four factors were significant at either the 5\% or the $10 \%$ levels: access to clients and household income. Thus, according to the results of the MRA analysis, the land use intensity and city reputation do not seem to help explain the percentage of T-KIBS jobs.

(Insert Table 2 about here)

After, taking a novel perspective, fsQCA was applied to identify the conditions to obtain the outcome being considered: a high percentage of T-KIBS jobs in a city. To assess the strength of the results, as per usual in fsQCA analyses, we used the values of consistency and 
coverage. Consistency is a measure of how closely a perfect subset relation is approximated (Ragin, 2008, p. 44), that is, how much the data "agree" with the relation considered. Coverage is a measure of the empirical relevance of a given relation (Ragin, 2008, p. 44), according to the data. The values of consistency and coverage range between zero and one. We started by performing an analysis of necessary conditions, that is, determining if the presence of any single factor is necessary to achieve the outcome. The results show that neither the presence nor absence of any of the factors is, by itself, necessary to achieve a high percentage of T-KIBS jobs. After this analysis, we undertook an analysis of sufficient conditions, that is, a search for configurations sufficient for the outcome to be obtained. The obtained results are presented in Table 3.

(Insert Table 3 about here)

As observed in Table 3, two configurations achieve a high percentage of T-KIBS jobs: one consisting of factors F1 and F3 (i.e., access to clients and city reputation) and the other consisting of F1, F2, and F4 (i.e., access to clients, land use intensity, and household income). The consistency of both configurations is greater than 0.85 , and the overall consistency is also close to 0.85 , indicating that the configurations consistently lead to the outcome, that is, each one should be sufficient to obtain a high percentage of T-KIBS jobs. The coverage is acceptable, although only a limited number of cases falls into each one. The first configuration, consisting of factors F1 and F3, has a higher overall coverage (0.589 vs. 0.402 of the second one) and a much higher unique coverage ( 0.247 vs. 0.060 of the second one), meaning it is more meaningful because it was obtained by a larger number of cities with a high level of KIBS jobs. The overall coverage of the set of two configurations is better than the individual values, 0.649, but still indicates that some cities may achieve a high percentage of T-KIBS jobs without following these configurations. This result is consistent with the results of the analysis of necessary conditions. Notably, both configurations include factor F1, which highlights the 
importance of the proximity to the market. This insight contrasts with the results of previous research that found this factor to be unimportant for location choices (e.g., Frenkel, 2001), but it is in line with the literature that highlights the importance of geographical proximity (e.g., McCann, 2007). Despite declining transport costs and the development of ICT, the co-location with clients and competitors can be important for several reasons. First, it provides immediate market knowledge, which can be crucial for T-KIBS competitiveness. Second, the proximity between actors promotes interactions, which can lead to innovations (e.g., Cooke et al., 2004; Porter, 2003). Third, T-KIBS can benefit from agglomeration economies tend to occur at a city level (Parr, 2002) due to cost saving mechanisms (Puga, 2010), that is, urbanization economies also justify the high percentage of T-KIBS in some cities.

Comparing the results of the analysis of sufficient conditions with the results of MRA analysis is also notable. Although MRA found only two significant factors, fsQCA shows that the other factors may also have a role in achieving the outcome. F3 (city reputation), a factor that was not significant in MRA analysis, when combined with F1 (access to clients), can lead to the outcome of interest. F2 (land use intensity), also not significant in the MRA, will also lead to the outcome if accompanied by F1 and F4. Notably, fsQCA uncovers two paths to obtain a high percentage of T-KIBS jobs, which MRA does not show. These results show that no condition alone nor any configuration (i.e., combination of conditions) is either necessary or sufficient to account for T-KIBS location. This indicates that linear approaches do not capture the whole picture and supports the idea that one-size-fits-all templates to explain urban dynamics have shortcomings. This insight should be taken in account in future research and provides an important clue for policy-makers.

Tables 4 and 5 present selected results related to the codification of the fuzzy degrees of membership and the analysis of sufficient conditions. Table 4 considers the cities with highest percentage of KIBS jobs (degree of membership of at least 0.5 in the outcome) and 
shows how the outcome and factor values were codified as fuzzy degrees of membership, as well as the degree of membership in each of the configurations obtained in the analysis of sufficient conditions. Additionally, the configurations for which each city has a degree of membership larger or equal than 0.5 are presented in the last column of Table 4 . Looking at this column, it is possible to confirm that some cities can achieve a high level of T-KIBS jobs without having a high degree of membership in any of the obtained configurations. At the top of Table 4, we observe that the majority, namely, 16 out of the 20 cities with the highest percentage of T-KIBS jobs, has a high degree of membership in at least one of the configurations.

(Insert Table 4 about here)

Table 4 shows that when the cities with a high percentage of T-KIBS jobs have a high degree of membership in just one configuration, the configuration tends to be the first, which corresponds to the joint presence of access to clients and city reputation. This phenomenon is in line with the coverage values of the configurations. However, there are some exceptions, and the most notable is Leverkusen. This city has a high percentage of T-KIBS jobs and a very low degree of membership in the first configuration (just 0.05 ), but exhibits a higher degree of membership in the second one (0.52).

A possible method to assess the ability of the configurations to identify the cities with a high percentage of T-KIBS jobs is to determine the proportion of cities with a high degree of membership in the outcome from those that have a high degree of membership in the configurations. There are 18 cities with a degree of membership in configuration 1 higher than 0.5. Only 2 of these 18 cities have a low degree of membership in the outcome, leading us to conclude that this configuration is successful in identifying cities with a high percentage of TKIBS jobs. A similar conclusion can be drawn for configuration 2. Eight out of ten cities with a degree of membership higher than 0.5 in this configuration also have a degree of membership 
in the outcome of 0.89 or more. Of the two remaining cities, one has a degree of membership of 0.5 in the outcome, leaving only one city with a low degree of membership in the outcome. A similar type of analysis could be performed for cities with low concentration of T-KIBS, in order to find the most promising path to obtain a high percentage of T-KIBS jobs.

\section{Discussion and conclusion}

This study aims to examine the influence of city reputation on T-KIBS location and to identify combinations of conditions that lead to a high concentration of T-KIBS in urban areas. The results of the principal component analysis revealed the presence of four factors that explain T-KIBS' location (Table 1): i) access to clients, ii) land use intensity, iii) city reputation, and $i v$ ) household income. The most notable result is perhaps the presence of the "City reputation". This factor has recently been suggested to be important for location decision (Delgado-Garcia et al., 2018), but empirical evidence was lacking. The four factors explain approximately $88 \%$ of the total variance. The highest explanatory factor is access to market, accounting for approximately $34 \%$ of the total variance, followed by land use intensity and city reputation (approximately 22\% each) and the household income (approximately 10\%). The regression analysis (Table 2) corroborated the explanatory power of access to market, which is significant at $1 \%$. Among the other factors, only household income appears to be significant at $5 \%$ in explaining the level of KIBS employment.

In contrast with past research, a configurational analysis was performed (Table 3), which provided new insights. Two configurations of conditions leading to T-KIBS location were observed: access to market combined with city reputation, or access to market in conjunction with both land use intensity, and household income. These findings emphasize the importance of access to market but also uncover a new path to T-KIBS location that includes 
city reputation. Tourism reflects city reputation, and research that links tourism with KIBS has been scarce, to say the least. Therefore, this study advances the understanding of T-KIBS location and introduces a new factor (city reputation) that can contribute to the concentration of T-KIBS in certain cities. Tourism firms that need the knowledge provided by T-KIBS to improve their competitiveness. Because T-KIBS must interact with their customers to produce this knowledge, which is often co-created (Petri \& Jacob, 2016), the development of tourism can contribute to the creation and to the development of T-KIBS. The obtained results support the idea that geographical proximity with clients is also important in technology-related industries, in particular the ones that are knowledge intensive. The findings suggest that tourism policies that enhance the city reputation can be included in cities' strategies designed to attract business services. However, policy-makers do not need to improve all conditions to improve the city competitiveness and they can use different combinations of factors to attract T-KIBS.

This study has limitations that could be addressed in future research. The findings confirm the relevance of using fsQCA to unravel causally complex structures, but they failed to capture the dynamics of business services. Considering that business services are evolving; future research could attempt to capture changes. Furthermore, the research was limited to the public data made available by Eurostat, but some countries and cities have additional data that could be used. Taking into consideration that some cities, like Heilbronn, are not covered by any of the obtained configurations, but have high percentage of T-KIBS, it is likely that different combinations of conditions may occur that involve other factors (beyond the scope of this study). Moreover, although the simplifications used to measure the factors are in line with the literature, it is possible that some findings present some ambiguity, which could be clarified with additional research. Therefore, we strongly recommend the use of different measures and the application of this study to other contexts to improve the generalizability of the findings. 


\section{References}

Andersson, M., \& Hellerstedt, K. (2009). Location attributes and start-ups in knowledge-intensive business services. Industry and Innovation, 16(1), 103-121.

Anttiroiko, A. (2015). City branding as a response to global intercity competition, Growth and Change, 46(2), 233-252.

Aslesen H.W., \& Jakobsen, S-E. (2007). The role of proximity and knowledge interaction between head offices and KIBS. Tijdschrift voor Economische en Sociale Geografie, 98(2): 188-201.

Aula, P., \& Harmaakorpi, V. (2008). An innovative milieu - A view on regional reputation building: Case study of the Lahti urban region, Regional Studies, 42(4), 523-538.

Autant-Bernard, C., Mangematin, V., \& Massard, N. (2006) Creation of biotech SMEs in France. Small Business Economics, 26(2), 173-187.

Bentlage, M., Lüthi, S., \& Thierstein, A. (2013). Knowledge creation in German agglomerations and acessibility - An approach involving non-physical connectivity. Cities 30, 47-58.

Berger, E.S. (2016). Is Qualitative Comparative Analysis an Emerging Method? - Structured Literature Review and Bibliometric Analysis of QCA Applications in Business and Management Research. In E.S.C. Berger \& A. Kuckertz (Eds.), Complexity in Entrepreneurship, Innovation and Technology Research, Applications of Emergent and Neglected Methods (pp. 287-308). Switzerland AG: Springer International Publishing.

Borodako, K., Berbeka, J., \& Rudnicki, M. (2015). Tourism enterprises as buyers of knowledgeintensive business services. SAGE Open, January-March, 1-10.

Boschma, R. (2005). Proximity and innovation: A critical assessment. Regional Studies, 39(1), 6174.

Breschi, S. (2008). Innovation-specific agglomeration economies and the spatial clustering of innovative firms. In C. Karlsson (Ed.), Handbook of Research on Innovation and Clusters (pp. 167-190), London: Edward Elgar.

Buch, T., Hamann, S., Niebuhr, A., \& Rossen, A. (2014). What makes cities attractive? The determinants of urban labour migration in Germany. Urban Studies, 51(9), 1960-1978.

Camacho-Ballesta, J.A., Melikhova, Y., \& Hernández-Peinado, M. (2014). Localization of Business Services in European Regions: Large Urban Areas Stand Out. European Planning Studies, 22(10), 2094-2115.

Coffey, W.J. (1996). Forward and backward linkages of producer-services establishments: Evidence from the Montreal metropolitan area. Urban Geography, 17(7), 604-632.

Cooke, P., Heidenreich, M., \& Braczyk, H-J. (2004). Regional Systems of Innovation: The Role of Governance in a Globalized World. London: Routledge.

Corrocher, N., \& Cusmano, L. (2014). The "KIBS engine" of regional innovation systems: Empirical evidence from European regions. Regional Studies, 7, 1212-1226.

Czarnitzki, D., \& Spielkamp, A. (2003). Business services in Germany: Bridges for innovation. Services Industries Journal, 23(2), 1-30.

D’Antone, S., \& Santos, J.B. (2016). When purchasing professional services supports innovation. Industrial Marketing Management, 58, 172-186.

Delgado-Garcia, J.B., de Quevedo-Puente, E., \& Blanco-Mazagatos, V. (2018). The impact of city reputation on city performance. Regional Studies, 52(8), 1098-1110.

Fiss, P.C. (2011). Building better causal theories: A fuzzy set approach to typologies in organization research. Academy of Management Journal, 54, 393-420. 
Florida, R. (2002). The rise of the creative class: And how it's transforming work, leisure, community and everyday life. New York: BasicBooks.

Florida, R., Adler, P., \& Mellander, C. (2017). The city as innovation machine. Regional Studies, 51(1), 86-96.

Frenkel, A. (2001). Why high-technology firms choose to locate in or near metropolitan areas. Urban Studies, 38(7), 1083-1101.

Grabher, G. (2002). Cool projects, boring institutions: temporary collaboration in social context. Regional Studies, 36, 205-214.

Granger, M.D., \& Blomquist, G.C. (1999). Evaluating the influence of amenities on the location of manufacturing establishments in urban areas. Urban Studies, 36(11), 1859-1873.

Hall, P. (1999). The future of cities. Computer, Environment and Urban Systems, 23(3), 173-185.

Henning, M. (2019). Regional labour flows between manufacturing and business services: Reciprocal integration and uneven geography. European Urban and Regional Studies, (in press), https://doi.org/10.1177/0969776419834065.

Herstad, S.J., \& Ebersberger, B. (2015). On the link between urban location and the involvement of knowledge-intentisive business services firms in collaboration networks. Regional Studies, 49(7), 1160-1175.

Hertog, D.P. (2000). Knowledge-intensive business services as co-producers of innovation. International Journal of Innovation Management, 4, 491-528.

Isaksen, A. (2004). Knowledge-based clusters and urban location: The clustering of software consultancy in Oslo, Urban Studies, 41(5/6), 1157-1174.

Jacobs, J. (1969). The economy of cities. New York: Random House.

Jacobs, W., van Rietbergen, T., Atzema, O., van Grunsven, L., \& van Dongen, F. (2016). The impact of multinational enterprises (MNEs) on knowledge-intensive business services (KIBS) startups: empirical evidence from the Dutch Randstad. Regional Studies, 50(4), 728-743.

Kahn, J.A., \& Henderson, D.A. (1992). Location preferences of family firms: Strategic decision making or "home sweet home?". Family Business Review, 5(3), 271-282.

Koster, H.R.A., van Ommeren, J., \& Rietveld, P. (2014). Estimation of semiparametric sorting models: Explaining geographical concentration of business services. Regional Science and Urban Economics, 44, 14-28.

Lambregts, B. (2008). Geographies of knowledge formation in mega-city regions: some evidence from Dutch Randstad. Regional Studies, 42(8), 1173-1186.

Lundvall, B-Å. (2007). National innovation systems: analytical concept and development tool. Industry and Innovation, 14(1), 95-119.

Marshal, N., \& Wood, P. (1995). Services \& space. Key aspects of urban and regional development. Singapore: Longman Singapure Publishers.

Martinelli, F. (1991). Producer services' location and regional development, in: P. W. Daniels \& F. Moulaert (Eds.). In The Changing Geography of Advanced Producer Services: Theoretical and Empirical Perspectives (pp. 70-90). London: Belhaven Press.

McCann, P. (2007). Sketching out a model of innovation, face-to-face interaction and economic geography. Spatial Economic Analysis, 2(2), 117-134.

Méndez, R., \& Sánchez Moral, S. (2010). Spanish cities in knowledge economy: Theoretical debates and empirical evidence. European Urban and Regional Studies, 18(2), 136-155. 
Miles, I, Kastrinos, N., Flanagan, K., Bilderbeek, R., Den Hertog, P., Huntik, W., \& Bouman, M. (1995). Knowledge intensive business services: Users, carriers and sources of innovation. European Innovation Monitoring System. Brussels, Belgium: European Commission.

Miles, I. (2005). Knowledge intensive business services: Prospects and policies, Foresight, 7(6), 3963.

Muller, E., \& Zenker, A. (2001). Business services as actors of knowledge transformation: The role of KIBS in regional and national innovation systems. Research Policy, 30(9), 1501-1516.

Navarro, S., Llinares, C., \& Garzon, D. (2016). Exploring the relationship between cocreation and satisfaction using QCA. Journal of Business Research, 69, 1336-1339.

Novelli, M., Schmitz, B., \& Spencer, T. (2006). Networks, clusters and innovation in tourism: a UK experience. Tourism Management, 27, 1141-1152.

Ordanini, A., Parasuraman, A., \& Rubera, G. (2014). When the recipe is more important than the ingredients a Qualitative Comparative Analysis (QCA) of service innovation configurations. Journal of Service Research, 17, 134-149.

Parr, J. (2002). Agglomeration economies: ambiguities and confusions. Environment \& Planning A, $34,717-731$.

Peck, J. (2017). Transatlatic city, part I: Conjunctural urbanism. Urban Studies, 54(1), 4-30.

Petri, J., \& Jacob, F. (2016). The customer as enabler of value (co)-creation in solution business. Industrial Marketing Management, 56, 63-72.

Puga, D. (2010). The magnitude and causes of agglomeration economies. Journal of Regional Science, 50(1), 203-219.

Racherla, P., \& Hu, C. (2010). A social network perspective of tourism research collaborations. Annals of Tourism Research, 37, 1012-1034.

Ragin, C.C. (2008). Redesigning social inquiry: Fuzzy sets and beyond. Chicago: University of Chicago Press.

Ragin, C.C. (2009). Qualitative comparative analysis using fuzzy sets (fsQCA). In: Ragin, C.C. \& Rihoux, B. (Eds.) Configurational comparative methods: qualitative comparative analysis (QCA) and related techniques (pp. 87-122). Los Angeles: Sage.

Rihoux, B., Rezsöhazy, I., \& Bol, D. (2011). Qualitative comparative analysis (QCA) in public policy analysis: an extensive review. German Policy Studies, 7(3), 9-82.

Roberts, P. W., \& Dowling, G. R. (2002). Corporate reputation and sustained superior financial performance, Strategic Management Journal, 23, 1077-1093.

Rubalcaba, L., Gallego, J., Gallo, M.T., \& Garrido, R. (2013) Business services location and market factors in major European cities. Cities, 31, 258-266.

Rubalcana, L., \& Gago, D. (2003). Regional concentration of innovative business services: Testing some explanatory factors at European regional level. The Service Industries Journal, 23(1), 77-94.

Ryan, J.C., \& Berbegal-Mirabent, J. (2016). Motivational recipes and research performance: A fuzzy set analysis of the motivational profile of high performing research scientists. Journal of Business Research, 69(11), 5299-5304.

Sassen, S. (2000). Cities in the Global Economy. In: Paddison, R. (Eds.), Handbook of Urban Studies (pp. 256-272). London: Sage.

Scott, A. (2006). Creative cities: Conceptual issues and policy questions. Journal of Urban Affairs, $28(1), 1-17$. 
Shearmur, R. (2012). The geography of intrametropolitan KIBS innovation: Distinguishing agglomeration economies from innovation dynamics. Urban Studies, 49(11), 2331-2356.

Shearmur, R., \& Doloreux, D. (2008). Urban hierarchy or local buzz? High-order producer service and (or) knowledge-intensive business service location in Canada 1991-2001. The Professional Geographer, 60(3), 333-355.

Shearmur, R., \& Doloreux, D. (2015). Central places or networksP Paradigms, metaphors, and spatial configurations of innovation-related service use. Environmental and Planning A, 47, 15211539 .

Simmie, J., \& Strambach, S. (2006). The contribution of KIBS to innovation in cities: An evolutionary and institutional perspective. Journal of Knowledge Management, 10(5), 2640.

Storper, M., \& Venables, A.J. (2004). Buzz: Face-to-face contact and the urban economy. Journal of Economic Geography, 4(4), 351-370.

Strambach, S. (2008). Knowledge-intensive business services (KIBS) as drivers of multilevel knowledge dynamics. International Journal of Services and Technology Management, 10, $152-174$.

Torre, A. (2008). On the role played by temporary geographical proximity in knowledge transmission, Regional Studies, 42(6), 869-889.

Torre, A., \& Rallet, A. (2005). Proximity and localization. Regional Studies, 39(1), 47-59.

Torres, P., Augusto, M., \& Godinho, P. (2017). Predicting high consumer-brand identification and high repurchase: necessary and sufficient conditions. Journal of Business Research, 79, 52 65 .

Wæraas, A. (2015). Making a difference: Strategic positioning in municipal reputation building, Local Government Studies, 41(2), 280-300.

Wood, P. (2002). Knowledge-intensive services and urban innovativeness. Urban Studies, 39(5-6), 993-1002.

Wood, P. (2006). Urban development and knowledge-intensive business services: Too many unanswered questions?, Growth and Change, 37(3), 335-361.

Wood, P. (2009). Service competitiveness and urban innovation policies in the UK: the implications of the 'London Paradox", Regional Studies, 43(8), 1047-1059.

Yamamura, S., \& Goto, H. (2018). Location patterns and determinants of knowledge-intensive industries in the Tokyo Metropolitan Area, Japan Architectural Review, 1(4), 443-456.

Yang, W., \& Yan, M. (2010). The policy to promote the innovative development of knowledge intensive business services, International Journal of Business Management, 5, 190-194. 
Table 1: Factorial analysis

\begin{tabular}{|c|c|c|c|c|}
\hline Variables & F1 & $\mathrm{F} 2$ & $\mathrm{~F} 3$ & F4 \\
\hline Economically active population (logarithm) & 0.945 & & & \\
\hline Total employment (logarithm) & 0.935 & & & \\
\hline Number of companies (logarithm) & 0.940 & & & \\
\hline Population density (inhabitants per square meter) & & 0.661 & & \\
\hline $\begin{array}{l}\text { Share of land-Industrial, commercial, public, military } \\
\text { and private units }(\%)\end{array}$ & & 0.912 & & \\
\hline Share of land-Transportation infrastructure (\%) & & 0.675 & & \\
\hline $\begin{array}{l}\text { Share of land - Green urban areas and sports and leisure } \\
\text { facilities (\%) }\end{array}$ & & 0.677 & & \\
\hline $\begin{array}{l}\text { Museum visitors (visits per year divided by the number } \\
\text { of inhabitants) }\end{array}$ & & & 0.793 & \\
\hline $\begin{array}{l}\text { Total nights spent in tourist accommodation } \\
\text { establishments (divided by the number of inhabitants) }\end{array}$ & & & 0.928 & \\
\hline $\begin{array}{l}\text { Number of beds in tourist accommodation } \\
\text { establishments (divided by the number of inhabitants) }\end{array}$ & & & 0.914 & \\
\hline $\begin{array}{l}\text { Average disposable annual household income } \\
\text { (logarithm) }\end{array}$ & & & & 0.969 \\
\hline$\%$ of explained variance & 33.9 & 21.9 & 21.6 & 10.4 \\
\hline Cumulative $\%$ of explained variance & 33.9 & 55.8 & 77.3 & 87.7 \\
\hline Eigenvalue & 5.15 & 2.36 & 1.11 & 1.02 \\
\hline
\end{tabular}

Note: Extraction method: Principal Components Analysis. Rotation method: Varimax with Kaiser normalization. Kaiser-Meyer-Olkin (KMO) index: 0.721 . Variance explained: $87.7 \%$. Only loadings higher than 0.65 (in absolute value) are shown in the table. F1 = Access to clients, F2 = Land use intensity, F3 = City reputation, F4 = Household income. 
Table 2: Regression analysis

\begin{tabular}{ccc}
\hline Variable & Coefficient & t-Statistic \\
\hline Constant & $0.181^{* * * *}$ & 11.22 \\
F1 & $0.071^{* * *}$ & 4.38 \\
F2 & 0.003 & 0.18 \\
F3 & 0.020 & 1.22 \\
F4 & $0.038^{* *}$ & 2.32 \\
& & \\
Number of observations & 75 & \\
$\mathrm{R}^{2}$ & 0.272 & \\
Adjusted R & 0.230 & \\
F-statistic $(\mathrm{F}(4,70)$ ) & $6.53^{* * *}$ &
\end{tabular}

Dependent variable: percentage of T-KIBS jobs.

${ }^{* * *},{ }^{* *},{ }^{*}$ Significant at $1 \%, 5 \%$, and $10 \%$, respectively.

$\mathrm{F} 1=$ Access to clients, F2 = Land use intensity, F3 = City reputation, F4 = Household income. 
Table 3: Configurations leading to T-KIBS location

\begin{tabular}{lcc}
\hline Configuration & 1 & 2 \\
\hline F1 & & \\
F2 & & \\
F3 & & \\
F4 & & \\
& & \\
C1 & 0.879 & 0.891 \\
C2 & 0.589 & 0.402 \\
C3 & 0.247 & 0.060 \\
Overall C1 & & \\
Overall C2 & 0.846 & \\
\hline
\end{tabular}

Note: C1: Consistency, C2: Coverage, C3: Unique coverage, F1 = Access to clients, F2 = Land use intensity, F3 = City reputation, F4 $=$ Household income, and $\sim$ represents the absence of the condition. Black circles indicate the presence of a condition; blank spaces indicate "don't care." 
Table 4: Degrees of membership in the factors, outcome and configurations, and configurations leading to a degree of membership of at least 0.50 in T-KIBS

\begin{tabular}{|c|c|c|c|c|c|c|c|c|}
\hline City & $\mathrm{F} 1$ & $\mathrm{~F} 2$ & F3 & $\mathrm{F} 4$ & KIBS & $\begin{array}{c}\text { Conf. } \\
1\end{array}$ & $\begin{array}{c}\text { Conf. } \\
2\end{array}$ & $\begin{array}{l}\text { Configs. with T- } \\
\text { KIBS membership } \\
\geq 0.50\end{array}$ \\
\hline Heilbronn & 0.51 & 0.16 & 0.19 & 0.95 & 1 & 0.19 & 0.16 & None \\
\hline Mainz & 0.7 & 0.54 & 0.65 & 0.94 & 1 & 0.65 & 0.54 & Both \\
\hline Darmstadt & 0.7 & 0.07 & 0.65 & 0.98 & 0.99 & 0.65 & 0.07 & 1 \\
\hline Karlsruhe & 0.82 & 0.43 & 0.59 & 0.89 & 0.98 & 0.59 & 0.43 & 1 \\
\hline Leipzig & 0.94 & 0.61 & 0.75 & 0.01 & 0.98 & 0.75 & 0.01 & 1 \\
\hline München & 0.99 & 0.84 & 0.95 & 0.99 & 0.97 & 0.95 & 0.84 & Both \\
\hline Köln & 0.99 & 0.66 & 0.7 & 0.57 & 0.97 & 0.7 & 0.57 & Both \\
\hline Nürnberg & 0.9 & 0.9 & 0.83 & 0.6 & 0.94 & 0.83 & 0.6 & Both \\
\hline Potsdam & 0.54 & 0.11 & 0.96 & 0.34 & 0.94 & 0.54 & 0.11 & 1 \\
\hline Frankfurt am Main & 0.98 & 0.67 & 0.98 & 0.98 & 0.91 & 0.98 & 0.67 & Both \\
\hline Leverkusen & 0.56 & 0.52 & 0.05 & 0.74 & 0.91 & 0.05 & 0.52 & 2 \\
\hline Berlin & 1 & 0.62 & 0.91 & 0.11 & 0.89 & 0.91 & 0.11 & 1 \\
\hline Stuttgart & 0.97 & 0.59 & 0.8 & 0.95 & 0.89 & 0.8 & 0.59 & Both \\
\hline Düsseldorf & 0.97 & 0.65 & 0.89 & 0.93 & 0.89 & 0.89 & 0.65 & Both \\
\hline Hamburg & 1 & 0.2 & 0.7 & 0.79 & 0.89 & 0.7 & 0.2 & 1 \\
\hline Ulm & 0.43 & 0.18 & 0.73 & 0.95 & 0.81 & 0.43 & 0.18 & None \\
\hline Offenbach am Main & 0.49 & 0.67 & 0.53 & 0.48 & 0.81 & 0.49 & 0.48 & None \\
\hline Hannover & 0.91 & 0.98 & 0.67 & 0.06 & 0.79 & 0.67 & 0.06 & 1 \\
\hline Saarbrücken & 0.8 & 0.06 & 0.39 & 0.21 & 0.77 & 0.39 & 0.06 & None \\
\hline Essen & 0.88 & 0.93 & 0.52 & 0.4 & 0.75 & 0.52 & 0.4 & 1 \\
\hline Fürth & 0.24 & 0.53 & 0.17 & 0.88 & 0.73 & 0.17 & 0.24 & None \\
\hline Oldenburg & 0.55 & 0.42 & 0.19 & 0.55 & 0.72 & 0.19 & 0.42 & None \\
\hline Kiel & 0.71 & 0.85 & 0.36 & 0.05 & 0.68 & 0.36 & 0.05 & None \\
\hline Erlangen & 0.41 & 0.22 & 0.72 & 1 & 0.64 & 0.41 & 0.22 & None \\
\hline Heidelberg & 0.2 & 0.2 & 0.99 & 0.74 & 0.62 & 0.2 & 0.2 & None \\
\hline Bremen & 0.92 & 0.71 & 0.45 & 0.29 & 0.62 & 0.45 & 0.29 & None \\
\hline Schwerin & 0.15 & 0.36 & 0.82 & 0.02 & 0.62 & 0.15 & 0.02 & None \\
\hline Flensburg & 0.03 & 0.9 & 0.51 & 0.32 & 0.61 & 0.03 & 0.03 & None \\
\hline Halle an der Saale & 0.59 & 0.76 & 0.23 & 0.03 & 0.6 & 0.23 & 0.03 & None \\
\hline Koblenz & 0.29 & 0.33 & 0.89 & 0.71 & 0.6 & 0.29 & 0.29 & None \\
\hline Ludwigshafen & 0.39 & 0.95 & 0.08 & 0.81 & 0.59 & 0.08 & 0.39 & None \\
\hline Dortmund & 0.92 & 0.6 & 0.08 & 0.33 & 0.59 & 0.08 & 0.33 & None \\
\hline Bayreuth & 0.12 & 0.22 & 0.76 & 0.34 & 0.56 & 0.12 & 0.12 & None \\
\hline Aschaffenburg & 0.06 & 0.53 & 0.24 & 0.86 & 0.54 & 0.06 & 0.06 & None \\
\hline Würzburg & 0.46 & 0.5 & 0.92 & 0.29 & 0.54 & 0.46 & 0.29 & None \\
\hline Gera & 0.45 & 0.02 & 0.25 & 0.07 & 0.52 & 0.25 & 0.02 & None \\
\hline Augsburg & 0.74 & 0.5 & 0.48 & 0.71 & 0.52 & 0.48 & 0.5 & 2 \\
\hline Mannheim & 0.75 & 0.9 & 0.6 & 0.92 & 0.5 & 0.6 & 0.75 & Both \\
\hline
\end{tabular}

Note: F1 = Access to clients, F2 = Land use intensity, F3 = City reputation, F4 = Household income 